\title{
Correction to: Service Evaluation of an Exercise on Referral Scheme for Adults with Existing Health Conditions in the United Kingdom
}

\author{
Grant J. McGeechan ${ }^{1} \cdot$ Dawn Phillips $^{2,3} \cdot$ Lynn Wilson $^{2,4} \cdot$ Vicki J. Whittaker $^{1} \cdot$ Gillian O'Neill $^{2}$. \\ Dorothy Newbury-Birch ${ }^{1}$
}

Published online: 20 April 2021

(C) International Society of Behavioral Medicine 2021

\section{Correction to: International Journal of Behavioral Medicine volume 25, pages 304-311(2018)}

The conclusion section in the abstract has been updated to read: The service has proven effective at increasing levels of physical activity among participants and has had a positive impact on waist circumference and BMI for clients who remain engaged with the programme. ("BMI" instead of "body").

Publisher's Note Springer Nature remains neutral with regard to jurisdictional claims in published maps and institutional affiliations.

The original article can be found online at https://doi.org/10.1007/ s12529-017-9699-3

Grant J. McGeechan

g.mcgeechan@tees.ac.uk

1 School of Health and Social Care, Constantine Building, Teesside University, Borough Road, Middlesbrough TS1 3BX, UK

2 Public Health Department, County Hall, Durham County Council, Durham DH1 5UJ, England

3 Children, Young People, and Families, North Tyneside Council, The Silverlink North, Cobalt Business Park, Quadrant, Newcastle upon Tyne NE27 0BY, England

4 Public Health, Gateshead Council, Civic Centre, Gateshead NE8 1HH, England 